\title{
A PATH ANALYSIS ON THE RISK FACTORS OF MULTIDRUG RESISTANTTUBERCULOSIS IN SURAKARTA, CENTRAL JAVA
}

\author{
Vera'), Setyo Sri Rahardjo $^{2)}$, Bhisma Murti1) \\ 1)Masters Program in Public Health, Universitas Sebelas Maret \\ ${ }^{2)}$ Faculty of Medicine, Universitas Sebelas Maret
}

\begin{abstract}
Background: Multidrug resistant TB (MDR-TB) is defined as a simultaneous resistance to at least rifampicin (RMP) and isoniazid (INH) two of the most important and effective "first-line" drugs. Patients infected with MDR strains are less likely to be cured from TB particularly if they are co-infected with HIV or suffer from other immuno suppressive diseases. MDR-TB is associated with a two to four fold period of treatment, psychological problems, economic wastage, poor treatment adherence and consequently treatment failure. This study aimed to analyze factors associated with MDR-TB using Health Belief Model and PRECEDE PROCEED model.
\end{abstract}

Subjects and Method: This was a case control study conducted at Dr. Moewardi Hospital and BBKPM Surakarta, Central Java, from September to November 2017. The study subjects were selected using fixed disease sampling, consisting of 76 MDR-TB patients and 228 TB patients. The dependent variable was MDR-TB. The independent variables were education level, self-efficacy, drug-taking adherence, smoking, nutritional status, perceived susceptibility, perceived barrier, perceived severity, perceived benefit, and drug-taking supervisor. The data were collected using questionnaire and analyzed by path analysis.

Results: The risk of MDR-TB increased with the lack of drug-taking adherence $(\mathrm{b}=-1.69 ; 95 \% \mathrm{CI}=-2.28$ to $-1.09 ; \mathrm{p}<0.001)$, poor nutritional status $(\mathrm{b}=1.32$; $95 \% \mathrm{CI}=0.72$ to $1.92 ; \mathrm{p}<0.001)$, and smoking $(\mathrm{b}=1.32 ; 95 \% \mathrm{CI}=0.72$ to 1.92 ; $\mathrm{p}<0.001)$. The risk of MDR-TB indirectly increased with perceived susceptibility, perceived severity, perceived benefit, drug-taking advisor, self efficacy, and low perceived barrier.

Conclusion: The risk of MDR-TB increases with the lack of drug-taking adherence, poor nutritional status, and smoking.

Keywords: Health belief model, PRECEDE-PROCEED, MDR-TB

\section{Correspondence:}

Vera. Masters Program in Public Health, Sebelas Maret University, Jl. Ir. Sutami 36 A, Surakarta 57126, Central Java. Email: vera21210@gmail.com 